\title{
Desenvolvimento de cultivares de soja em função do grupo de maturação e tipo de crescimento em terras altas e terras baixas
}

\author{
Alencar Junior Zanon ('); José Eduardo Minussi Winck ('); Nereu Augusto Streck( ${ }^{*}$ *); \\ Thiago Schmitz Marques da Rocha ( $\left.{ }^{1}\right)$; Jossana Ceolin Cera ( $\left.{ }^{1}\right)$; Gean Leonardo Richter ('); \\ Isabel Lago ('); Patrícia Marques dos Santos ( $\left.{ }^{2}\right)$; Leandro da Rosa Maciel (2); \\ Jerson Vanderlei Carús Guedes ( $\left.{ }^{3}\right)$; Enio Marchesan (1)
}

(1) Universidade Federal de Santa Maria (UFSM), Departamento de Fitotecnia, Avenida Roraima, 1.000, 97105-900 Santa Maria (RS), Brasil.

(2) Universidade Federal de Pelotas (UFPel), Faculdade de Agronomia Eliseu Maciel (FAEM), Departamento de Fitotecnia, Campus Universitário s/n, 96010-610 Capão do Leão (RS), Brasil.

(3) UFSM, Departamento de Defesa Fitossanitária, 97105-900 Santa Maria (RS), Brasil.

(*) Autor correspondente: nstreck2@yahoo.com.br

Recebido: 31/jan./2015; Aceito: 8/maio/2015

\section{Resumo}

O objetivo deste trabalho foi caracterizar o desenvolvimento de cultivares de soja com diferentes grupos de maturação e tipos de crescimento em terras altas e terras baixas no Rio Grande do Sul. Foram conduzidas nove épocas de semeadura em Santa Maria (ambiente de terras altas) e uma época de semeadura em Capão do Leão (ambiente de terras baixas) durante os anos agrícolas 2010/2011, 2011/2012 e 2012/2013, com 11 cultivares de soja. O delineamento experimental em todos os experimentos foi blocos ao acaso, em parcelas subdivididas. Foi quantificada a duração, em ${ }^{\circ} \mathrm{C}$ dia, do ciclo de desenvolvimento, da fase vegetativa e reprodutiva, e do período entre a data que ocorreu o início do florescimento e o número final de nós para todas as épocas e locais de semeadura. Houve redução da duração da fase reprodutiva, do ciclo total de desenvolvimento (exceto algumas cultivares semeadas em setembro), com o atraso da data de semeadura independentemente do grupo de maturação e tipo de crescimento. As semeaduras de setembro, janeiro e fevereiro promovem uma redução da fase vegetativa na maioria das cultivares quando comparadas com a época recomendada (novembro e dezembro). Cultivares indeterminadas apresentam um maior período de sobreposição das fases vegetativa e reprodutiva do que as cultivares determinadas em todas as épocas e locais de cultivo. $O$ desenvolvimento da soja é similar quando cultivada em terras altas e terras baixas.

Palavras-chave: Glycine max, época de semeadura, fenologia.

\section{Development of soybean cultivars as a function of maturation group and growth type in high lands and in lowlands}

\begin{abstract}
The objective of this study was to characterize the development of soybean cultivars with different maturity group, and growth types grown in highlands and in lowlands in Rio Grande do Sul. Field experiments were conducted in Santa Maria (highland) and Capão do Leão (lowland) during the 2010/2011, 2011/2012 and 2012/2013 growing seasons, with 11 treatments (soybean cultivars). Nine sowing dates were conducted in Santa Maria and one in Capão do Leão. The experimental design in all experiments was a randomized block design with split plots. The duration of the development cycle, vegetative and reproductive phases, and the period between the date that was the final number of nodes and early flowering was measured in ${ }^{\circ} \mathrm{C}$ day, for all sites and sowing dates. There was reduction in the duration of the reproductive phase, total development cycle (except some cultivars sown in september), with delay on sowing date regardless of the maturity group and type of growth with delayed sowing. Sowings of September, January and February promote a reduction in vegetative stage in most cultivars when compared with the recommended period (November and December). Cultivars Indeterminate have a longer period of overlap between the vegetative and reproductive phases than certain cultivars in all sites and sowing dates. The soybean development is similar when grown in highlands and lowlands.
\end{abstract}

Key words: Glycine max, sowing date, phenology. 


\section{INTRODUÇÃO}

A cultura da soja é a principal commodity agrícola do Brasil, que é o segundo maior produtor mundial do grão (CONAB, 2014). Houve um crescimento na produção e na produtividade da soja brasileira de $741,3 \%$ e $174,9 \%$, respectivamente, entre as safras de 1976/1977 e 2013/2014 (CONAB, 2014). No Rio Grande do Sul (RS), também houve essa tendência de aumento na área e na produtividade média da cultura da soja. Destaca-se o ano agrícola 2013/2014, quando foram cultivadas aproximadamente 4,9 milhóes de hectares e produzidas 13,2 milhôes de toneladas, sendo a maior safra de soja na história desse Estado (CONAB, 2014). Dessa área cultivada, aproximadamente 302.000 hectares foram cultivados em áreas de terras baixas em sucessão com a cultura do arroz (IRGA, 2014).

O aumento da área cultivada e da produtividade da soja no Brasil e, mais especificamente, no Rio Grande do Sul deve-se à incorporação de novas tecnologias de produção nos últimos anos. Por exemplo, a utilização de cultivares precoce (grupo de maturaçáo menor que 6.4) e com tipo de crescimento indeterminado, em substituição às cultivares semeadas até os anos 2000, que apresentavam quase na sua totalidade ciclo médio ou longo e tipo de crescimento determinado (Barni \& Matznauer, 2000). Destaca-se que o aumento da área cultivada com soja no RS deve-se ao fato de muitos agricultores estarem realizando semeaduras precoces (final de setembro e início de outubro) e tardias (final de dezembro e janeiro), permitindo assim dois cultivos no mesmo ano agrícola (Meotti et al., 2012). Verifica-se, também, o aumento do cultivo de soja em áreas de terras baixas, onde tradicionalmente vem sendo cultivado arroz irrigado por inundação (IRGA, 2014).

No Rio Grande do Sul, durante a estaçáo de cultivo da soja, a intensidade de radiação solar, o fotoperíodo e a temperatura média do ar aumentam nos meses de setembro a dezembro, e diminuem nos meses de janeiro a abril. A duraçáo das fases e do ciclo de desenvolvimento da soja é regulada pela temperatura e fotoperíodo (Kantolic, 2008), e varia com o genótipo e com o estágio de desenvolvimento da cultura (Setiyono et al., 2007). Por exemplo, o desenvolvimento das cultivares com grupos de maturação baixos é mais dependente da temperatura do ar que do fotoperíodo até o início do enchimento de grãos (Sinclair et al., 2005). A partir desse estágio, o desenvolvimento passa a ser mais afetado pelo fotoperíodo do que pela temperatura do ar (Grimm et al., 1994).

Esforços científicos com o objetivo de conhecer os estágios de desenvolvimento mais críticos para a determinação dos componentes de rendimento, sob diferentes condiçóes ambientais, tem sido tema de vários autores (Kantolic \& Slafer, 2005; Meotti et al., 2012). Assim, estudos básicos que descrevem de forma detalhada o desenvolvimento das novas cultivares de soja, em resposta às diferentes disponibilidades edafoclimáticas necessitam ser realizados no Rio Grande do
Sul e no Brasil. A caracterizaçáo da duraçáo das fases e do ciclo de desenvolvimento, em função do grupo de maturação e do tipo de crescimento, poderá auxiliar a assistência técnica e os produtores de soja a definirem práticas de manejo para alcançar o potencial genético de cada cultivar. Nesse sentido, o objetivo deste trabalho foi caracterizar o desenvolvimento de cultivares de soja com diferentes grupos de maturação e tipos de crescimento, em um local de terras altas e em um local de terras baixas, ambos no Estado do Rio Grande do Sul. A hipótese deste estudo é que quanto menor o grupo de maturação, menor será a duração do ciclo e das fases de desenvolvimento, independentemente do tipo de crescimento.

\section{MATERIAL E MÉTODOS}

Experimentos de campo foram conduzidos em Santa Maria, na Universidade Federal de Santa Maria (2943'S, $53^{\circ} 43^{\prime} \mathrm{W}$ e altitude de $95 \mathrm{~m}$ ), localizada na regiáo da Depressão Central do Rio Grande do Sul, e em Capáo do Leão, na Universidade Federal de Pelotas (31 $52^{\prime}$ 'S, 52 $21^{\circ}$ 'W e altitude de $13 \mathrm{~m}$ ), localizada na regiâo Sul do Rio Grande do Sul. O clima dos locais, segundo a classificação de Köppen, é do tipo Cfa, subtropical úmido com veróes quentes e sem estação seca definida (Kuinchtner \& Buriol, 2001). O solo da área experimental em Santa Maria é uma transição entre a Unidade de Mapeamento Sáo Pedro (Argissolo Vermelho distrófico arênico) e a Unidade de Mapeamento Santa Maria (Argissolo Bruno Acinzentado Alítico úmbrico), e é típico de terras altas no Rio Grande do Sul (solos bem drenados e que tradicionalmente cultivam-se culturas de sequeiro, como soja, milho, feijão etc.). O solo da área experimental de Capão do Leáo pertence à Unidade de Mapeamento Pelotas (Planossolo Háplico Eutrófico solódico) e é típico de terras baixas no Rio Grande do Sul (solos com deficiência de drenagem e que são utilizados para o cultivo de arroz irrigado) (Streck et al., 2008).

Foram utilizadas 11 cultivares de soja (Tabela 1), as quais foram selecionadas por representar diferentes grupos

Tabela 1. Cultivares de soja, grupo de maturação (GM) e tipo de crescimento utilizados nos experimentos de campo em Santa Maria e em Capão do Leão (RS)

\begin{tabular}{|lcc|}
\multicolumn{1}{c}{ Cultivares } & GM & Tipo de Crescimento \\
\hline NS 4823 RR & 4,8 & Indeterminado \\
\hline BMX ENERGIA RR & 5,5 & Indeterminado \\
\hline BMX TURBO RR & 6,0 & Indeterminado \\
\hline NA 5909 RG & 6,3 & Indeterminado \\
\hline IAS 5 & 6,4 & Determinado \\
\hline IGRA RA 518 RR & 6,6 & Semi-determinado \\
\hline BMX POTÊNCIA RR & 6,7 & Indeterminado \\
FEPAGRO 36 RR & 7,2 & Determinado \\
\hline BRS 246 RR & 7,2 & Determinado \\
BRAGG & 7,3 & Determinado \\
CD 219 RR & 8,2 & Determinado \\
\hline
\end{tabular}


de maturação (GM) e tipos de crescimento. Desde cultivares antigas, como IAS 5 e BRAGG, que foram cultivadas entre as décadas de 60 e 90 no Rio Grande do Sul, até cultivares modernas transgênicas. As cultivares de soja foram semeadas em diferentes épocas, antes, durante e após o período recomendado pelo Zoneamento Agroclimático da Soja para o Rio Grande do Sul. Foram realizadas nove datas de semeadura durante os anos agrícolas de 2010/2011 (10/12/2010 e 8/1/2011), 2011/2012 (24/9/2011, 19/11/2011 e 28/1/2012) e $2012 / 2013(22 / 9 / 2012,03 / 11 / 2012,2 / 12 / 2012$ e 6/2/2013), em Santa Maria, e uma data de semeadura no ano agrícola de 2012/2013 (9/11/2012), em Capão do Leão. A adubação de base, a inoculação das sementes com estirpes de Bradyrhizobium japonicum, o tratamento das sementes com fungicida e inseticida, e o controle de pragas e doenças foram realizados de acordo com as recomendaçôes técnicas da cultura. O controle de plantas daninhas foi realizado através de capinas manuais. Em Santa Maria, os experimentos foram conduzidos com irrigação suplementar de modo que o crescimento e o desenvolvimento das plantas ocorressem sem deficiência hídrica.

O delineamento experimental foi blocos ao acaso, em parcelas subdivididas, com quatro repetições. As épocas de semeadura constituíram as parcelas principais e as cultivares as subparcelas. Cada repetiçáo foi constituída de uma parcela com 11 fileiras de plantas e duas fileiras de bordadura. Cada fileira continha uma cultivar e teve $3 \mathrm{~m}$ de comprimento. $\mathrm{O}$ espaçamento foi de $0,45 \mathrm{~m}$ entre fileiras, na densidade de 30 plantas $\mathrm{m}^{-2}$ e profundidade de semeadura de $0,05 \mathrm{~m}$. A data de emergência foi considerada quando $50 \%$ do total de plantas de cada fileira estavam com os cotilédones acima do solo. Foram marcadas com arame colorido cinco plantas aleatoriamente, em cada fileira, logo após a emissão do primeiro par de folhas unifoliadas, para serem realizadas as contagens do número de nós e as avaliaçóes de fenologia. A data do número final de nós (NFN) foi considerada quando a haste principal não emitiu mais nós. Foram realizadas avaliaçôes diárias para identificar os estágios reprodutivos R1, R3, R5, R7 e R8, segundo a escala de Fehr \& Caviness (1977).

As temperaturas mínima e máxima diárias do ar, precipitação e radiação solar durante o período experimental foram coletadas em estaçôes meteorológicas convencionais, pertencentes ao $8 .^{\circ}$ Distrito de Meteorologia do Instituto Nacional de Meteorologia (DISME/INMET) e à Embrapa Cilma Temperado, localizadas, respectivamente, a aproximadamente cem metros da área experimental, tanto em Santa Maria como em Capão do Leão. A temperatura média (Tmed) diária do ar foi calculada pela média aritmética das temperaturas mínima e máxima. A soma térmica diária (STd, ${ }^{\circ} \mathrm{C}$ dia) foi calculada pelo método (Arnold, 1960):

$S T d=($ Tmed $-T b) *($ Idia $) \quad\{$ quandoTb $\leq$ Tmed $\leq$ Topl $(1)$ e

$$
\begin{aligned}
& \text { STd }=(\text { Tot }- \text { Tb }) \times\left(\frac{\text { Tmax }- \text { Tmed }}{\text { Tmax }- \text { Topt }}\right) \\
& \left\{\begin{array}{c}
\text { quando } \text { Topt }<\text { Tmed } \leq \text { Tmax, se Tmed }<\text { Tbentão } \\
\text { Tmed }=T b \text { e se Tmed }>\text { T max então Tmed }=\text { T max }
\end{array}\right.
\end{aligned}
$$

em que Tb é a temperatura base, Topt é a temperatura ótima e Tmax é a temperatura máxima para o desenvolvimento da soja. Foi utilizado $\mathrm{Tb}=7,6^{\circ} \mathrm{C}$, Top $\mathrm{t}=31^{\circ} \mathrm{C}$ e Tmax $=40^{\circ} \mathrm{C}$ para o cálculo da soma térmica da fase vegetativa (Semeadura-R1), e Tb $=0,0{ }^{\circ} \mathrm{C}$, Topt $=21,5^{\circ} \mathrm{C}$ e Tmax $=38,7{ }^{\circ} \mathrm{C}$ para o cálculo da soma térmica da fase reprodutiva (R1-R8) (Setiyono et al., 2007).

A soma térmica diária foi acumulada a partir da semeadura, resultando na soma térmica acumulada (STa), ou seja:

$S T a=\sum S T d$

Foi determinada a duraçáo, em ${ }^{\circ} \mathrm{C}$ dia, das fases semeadura à emergência (SEM-EM), emergência ao início do florescimento (EM-R1), início do florescimento à maturação plena (R1-R8), ciclo total (EM-R8) e das subfases: R1-R3, R3-R5, R5-R7 e R7-R8. Também foi determinada a data do aparecimento do último nó na haste principal e com esta data foi estimada a sobreposição das fases vegetativa e reprodutiva (do R1 até o NFN), em ${ }^{\circ} \mathrm{C}$ dia. A análise estatística foi realizada para as variáveis EM-R8, EM-R1, R1-R8 e R1-NFN para cada ano agrícola (2010/2011, 2011/2012 e 2012/2013) nos experimentos conduzidos em Santa Maria considerando um arranjo fatorial em parcelas subdivididas (parcela principal = época de semeadura e subparcelas = cultivares). A análise estatística realizada para os experimentos conduzidos em Santa Maria (semeadura em 3/11/2012) e em Capão do Leão (semeadura em 9/11/2012) foi considerando-se um bi-fatorial, com o fator A local de semeadura (dois níveis) e o fator $\mathrm{D}$ cultivares (11 níveis). As médias dessas variáveis foram distinguidas pelo teste de Duncan $(\mathrm{p}<0,05)$. Todas as análises estatísticas foram realizadas com auxílio do pacote estatístico SAS.

\section{RESULTADOS E DISCUSSÃO}

A análise de variância (ANOVA) mostrou efeito significativo dos fatores época de semeadura e cultivar para todas as variáveis nos experimentos conduzidos em Santa Maria de 2010 até 2013 (Tabela 2). O quadrado médio foi maior para o fator época de semeadura do que para o fator cultivar, exceto para as variáveis EM-R1 no ano agrícola 2010/2011 e para R1-NFN nos anos agrícolas 2010/2011 e $2012 / 2013$. O que indica que a maioria das variáveis foram mais afetadas pelo efeito ambiental do que pela constituição 
Tabela 2. Valores do quadrado médio da ANOVA para as variáveis duração do ciclo de desenvolvimento (EM-R8), duração da fase vegetativa (EM-R1), duração da fase reprodutiva (R1-R8), duração da sobreposiçâo da fase vegetativa e reprodutiva (R1-NFN), para onze cultivares de soja em duas datas de semeadura no ano agrícola 2010/2011, três datas de semeadura no ano agrícola 2011/2012, quatro datas de semeadura no ano agrícola 2012/2013 em Santa Maria, e os valores do quadrado médio da ANOVA para as mesmas variáveis (EM-R8, EM-R1, R1-R8 e R1-NFN) para 11 cultivares de soja e dois locais de semeadura (Santa Maria e Capão do Leão), RS, Brasil

\begin{tabular}{|c|c|c|c|c|c|c|c|c|}
\hline \multirow{3}{*}{ Causas de variação } & \multicolumn{8}{|c|}{ Quadrado Médio } \\
\hline & \multicolumn{4}{|c|}{ SM 2010-2011 } & \multicolumn{4}{|c|}{ SM 2011-2012 } \\
\hline & EM-R8 & EM-R1 & R1-R8 & NFN-R1 & EM-R8 & EM-R1 & R1-R8 & NFN-R1 \\
\hline Bloco (B) & $10572,6^{*}$ & $2289,8^{*}$ & $4834,2^{*}$ & 3058,2 & 15467,0 & 754,6 & 6848,3 & 4437,3 \\
\hline Época de Semeadura (A) & $298941,3^{*}$ & $135947,4^{*}$ & $31691,9^{*}$ & $68480,7^{*}$ & $4330197,4^{*}$ & $612086,6^{*}$ & $3964394,8^{*}$ & $824118,9^{*}$ \\
\hline$A \times B$ & $10211,6^{*}$ & $8926,7^{*}$ & 2448,8 & 4989,2 & 14313,4 & 1303,1 & 3614,7 & $6962,6^{*}$ \\
\hline Cultivar (D) & $222726,4^{*}$ & $139222,4^{*}$ & $29576,1^{*}$ & $124710,7^{*}$ & $369428,5^{*}$ & $263103,6^{*}$ & $64172,4^{*}$ & $316161,4^{*}$ \\
\hline$A \times D$ & $5330,7^{*}$ & $6191,4^{*}$ & $3959,1^{*}$ & $5157,6^{*}$ & $104988,9^{*}$ & $28052^{*}$ & $72122,2^{*}$ & $62003,9^{*}$ \\
\hline \multirow[t]{3}{*}{ Coeficiente de Variação (\%) } & 1,62 & 3,77 & 2,4 & 21,17 & 6,11 & 3,53 & 4,78 & 13,29 \\
\hline & \multicolumn{4}{|c|}{ SM 2012-2013 } & \multicolumn{4}{|c|}{ SM/PEL 2012-2013 } \\
\hline & EM-R8 & EM-R1 & R1-R8 & NFN-R1 & EM-R8 & EM-R1 & R1-R8 & NFN-R1 \\
\hline Bloco (B) & 6850,5 & $3295^{*}$ & 760,8 & 662,4 & 2576,1 & $1788,7^{*}$ & 2969,5 & 35,0 \\
\hline $\begin{array}{l}\text { Época ou Local de } \\
\text { Semeadura (A) }\end{array}$ & $3851405,6^{*}$ & $806874,5^{*}$ & $1788123,8^{*}$ & $60328,2^{*}$ & 1119,4 & $138699,2^{*}$ & $137477,3^{*}$ & $302176,2^{*}$ \\
\hline$A \times B$ & 5081,2 & 683,8 & 3923,3 & 1409,5 & 3432,2 & 304,3 & 4781,7 & 367,8 \\
\hline Cultivar (D) & $517200,1^{*}$ & $480177,2^{*}$ & $92158,9^{*}$ & $511590,5^{*}$ & $251017,6^{*}$ & $223616,2^{*}$ & $75615^{*}$ & $355908,6^{*}$ \\
\hline$A \times D$ & $37798,4^{*}$ & $26030,2^{*}$ & $19433,2^{*}$ & $31703,5^{*}$ & 3298,1 & $4698^{*}$ & 3244,2 & $13173,0^{*}$ \\
\hline Coeficiente de Variação (\%) & 2,4 & 3,61 & 3,51 & 14,00 & 2,27 & 2,43 & 3,7 & 14,88 \\
\hline
\end{tabular}

genética (Tabela 2). Já quando comparado às semeaduras realizadas em Santa Maria e Pelotas, a ANOVA mostrou efeito significativo para os fatores local de semeadura e cultivar somente para as variáveis EM-R1 e R1-NFN. A precisão experimental neste estudo pode ser classificada como alta, pois os coeficientes de variação para a maioria das variáveis analisadas foram inferiores ou próximos a $10 \%$ (Gomes, 1990).

As condições meteorológicas a que as cultivares de soja foram expostas nas diferentes épocas de semeadura, durante os três anos agrícolas, em Santa Maria e em Capão do Leão, estão expostas na figura 1. A menor e a maior duraçáo da fase SEM-EM foi de $89,2{ }^{\circ} \mathrm{C}$ dia na cultivar BRAGG, semeada em $24 / 9 / 2011$, e $175,9{ }^{\circ} \mathrm{C}$ dia na cultivar CD 219RR, semeada em 8/1/2011. Nas semeaduras de setembro, novembro/dezembro e janeiro, a soma térmica acumulada média na fase SEM-EM foi de $108,9{ }^{\circ} \mathrm{C}$ dia, $126,8{ }^{\circ} \mathrm{C}$ dia e $130,5^{\circ} \mathrm{C}$ dia, respectivamente. Verificando-se assim, um aumento da soma térmica acumulada com o atraso da semeadura. Essa resposta indica que alguns estudos numéricos fazem simplificações inapropriadas, como, por exemplo, Trentin et al. (2013) que generalizaram a duração desta fase como sendo de $92,5^{\circ} \mathrm{C}$ dia para qualquer época de semeadura, considerando uma temperatura base de $10^{\circ} \mathrm{C}$.

Em virtude das cultivares pertencerem a GM distintos, observou-se de maneira geral uma redução da duração total do ciclo, na mesma época de semeadura, com a redução do GM para todas as semeaduras, nos dois locais de cultivo (Figuras 2, 3, 4 e 5). Essa resposta de encurtamento da duraçáo do ciclo de desenvolvimento conforme a redução do grupo de maturação, concorda com os estudos de Mercau et al. (2007) e Trentin et al. (2013), que também verificaram que para uma mesma regiáo, quanto menor o GM, menor a duraçáo do ciclo. Há uma tendência de encurtamento da fase reprodutiva (R1-R8) e do ciclo de desenvolvimento (EM-R8) (exceto as cultivares NA 5909 RG e NS 4823 RR na semeadura de 22/9/2012) com o atraso da semeadura, em todos os anos agrícolas, em Santa Maria (Figuras 2, 3 e 4); concordando com os resultados encontrados por Stülp et al. (2009) e Trentin et al. (2013) e que pode ser explicada pelo efeito do fotoperíodo sobre o desenvolvimento da soja, a qual é uma planta de dia curto (Sinclair et al., 2005).

Considerando todas as épocas de semeadura, a menor e a maior duração da fase vegetativa ocorreram, respectivamente, nas cultivares NS $4823 \mathrm{RR}\left(369,6^{\circ} \mathrm{C}\right.$ dia) e CD $219 \mathrm{RR}$ (1402,7 ${ }^{\circ} \mathrm{C}$ dia), semeadas em $24 / 9 / 2011$. Já para fase reprodutiva, a cultivar BRAGG, semeada em 24/9/2011, apresentou a maior duraçáo $\left(2005,1{ }^{\circ} \mathrm{C}\right.$ dia $)$ e a cultivar CD 219 RR, semeada em 19/11/2011, apresentou a menor duração $\left(990,2^{\circ} \mathrm{C} \mathrm{dia}\right)$. As cultivares com tipo de crescimento determinado apresentaram uma maior proporção da fase vegetativa (42\%) no ciclo total, quando comparadas com as cultivares indeterminadas $(33,4 \%)$, nas semeaduras de novembro e dezembro (época recomendada). Como impactos positivos da maior duração da fase reprodutiva nas cultivares de tipo de crescimento indeterminado, pode-se inferir um provável aumento do potencial produtivo dessas cultivares (Setiyono et al., 2010). Em experimentos de campo e numéricos conduzidos por Kantolic et al. (2007) em Buenos Aires, Argentina, os autores verificaram que uma hipótese 

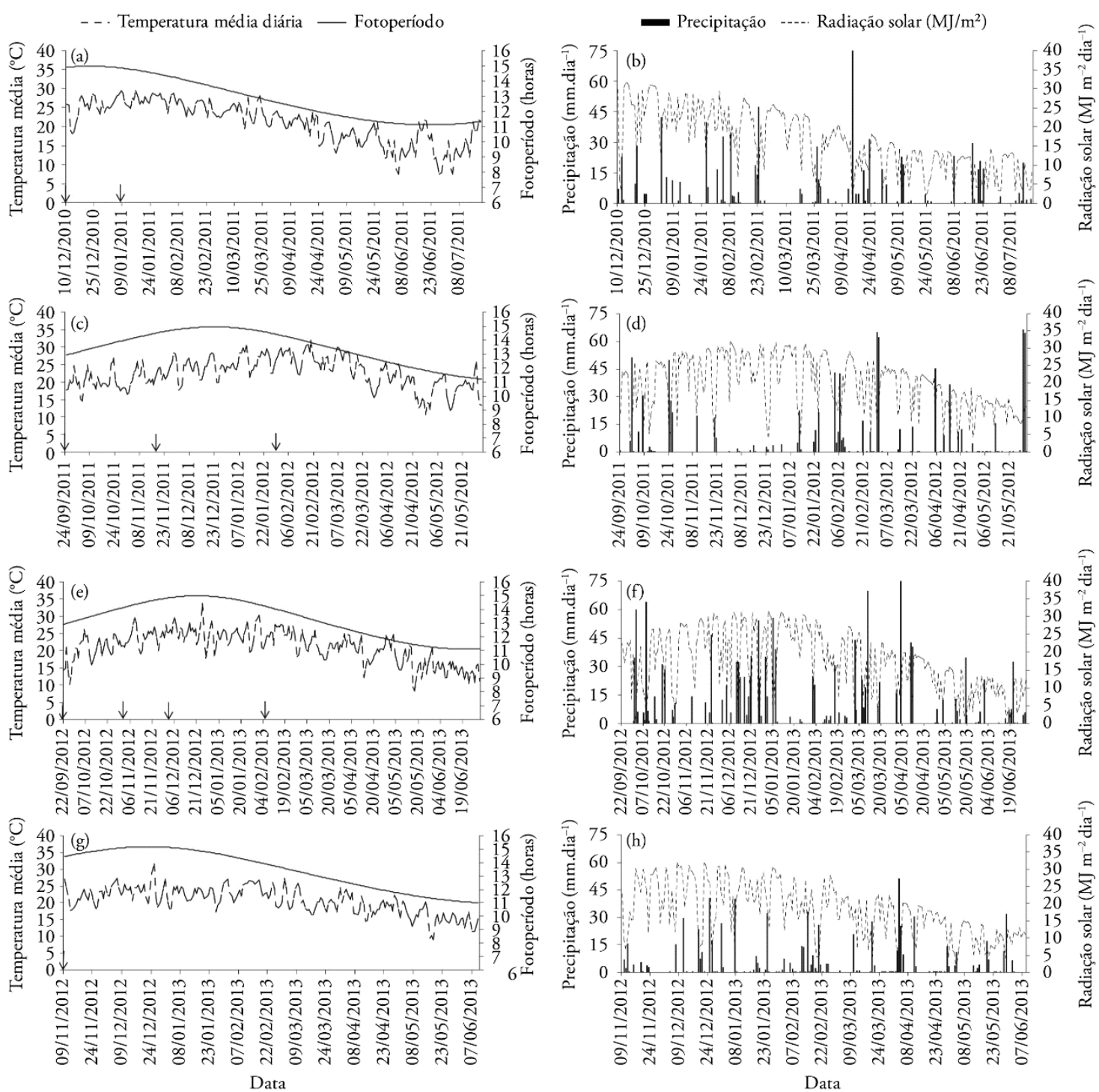

Figura 1. Temperatura média do ar $\left({ }^{\circ} \mathrm{C}\right)$ e fotoperíodo diários (horas) ((a), (c), (e) e $(\mathrm{g})$ ), e precipitação (mm dia $\left.{ }^{-1}\right)$ e densidade de fluxo de radiação solar global incidente $\left(\mathrm{MJ} \mathrm{m}^{-2} \mathrm{dia}^{-1}\right)$ ((b), (d), (f) e (h)), durante os experimentos em Santa Maria nos anos agrícolas 2010/2011, 2011/2012 e 2012/2013, e em Capão do Leão, no ano agrícola 2012/2013. As setas indicam as datas de semeadura.

para os programas de melhoramento de soja aumentarem a produtividade potencial da cultura seria através da seleção de cultivares com maior duração da fase reprodutiva, sem prolongar a duração do ciclo total de desenvolvimento.

As cultivares apresentaram uma reduçáo da fase vegetativa (EM-R1), quando semeadas antes ou após a época recomendada (setembro, janeiro e fevereiro), nos anos agrícolas de 2011/2012 e 2012/2013 (Figuras 3, 4). A antecipação do florescimento nessas datas de semeadura, deve-se ao fotoperíodo curto (12-13 horas) a que as cultivares foram expostas no início do ciclo de desenvolvimento (Sinclair et al., 2005) nas semeaduras de setembro, janeiro e fevereiro. Kantolic (2008) verificou que semeaduras antecipadas de primavera, em latitudes médias, apresentaram uma tendência de acelerar a iniciação floral, da mesma maneira que em semeaduras tardias. Esse efeito foi mais pronunciado nas cultivares antigas que não possuem o gene de juvenilidade, como a BRAGG, que, semeada em 24/9/2011 e 22/9/2012, floresceu em 18/11/2011 e 14/11/2012, respectivamente. Estudos com época de semeadura de soja no RS utilizando cultivares determinadas, verificaram que a antecipação do florescimento, provocava a redução do porte das plantas e da altura de inserção dos legumes inferiores, reduzindo a produtividade de grãos em algumas cultivares de soja, e consequentemente, inviabilizando o cultivo fora da época recomendada (novembro e dezembro) (Bonato et al., 1998). Essa resposta foi um dos fatores que inviabilizaram a antecipaçáo e o atraso da data de semeadura da cultura da soja nas décadas de 70, 80 e 90 no RS. Porém, com o aumento da utilização de cultivares indeterminadas, esse problema foi minimizado, pois apesar das mesmas também florescerem precocemente quando semeadas fora 


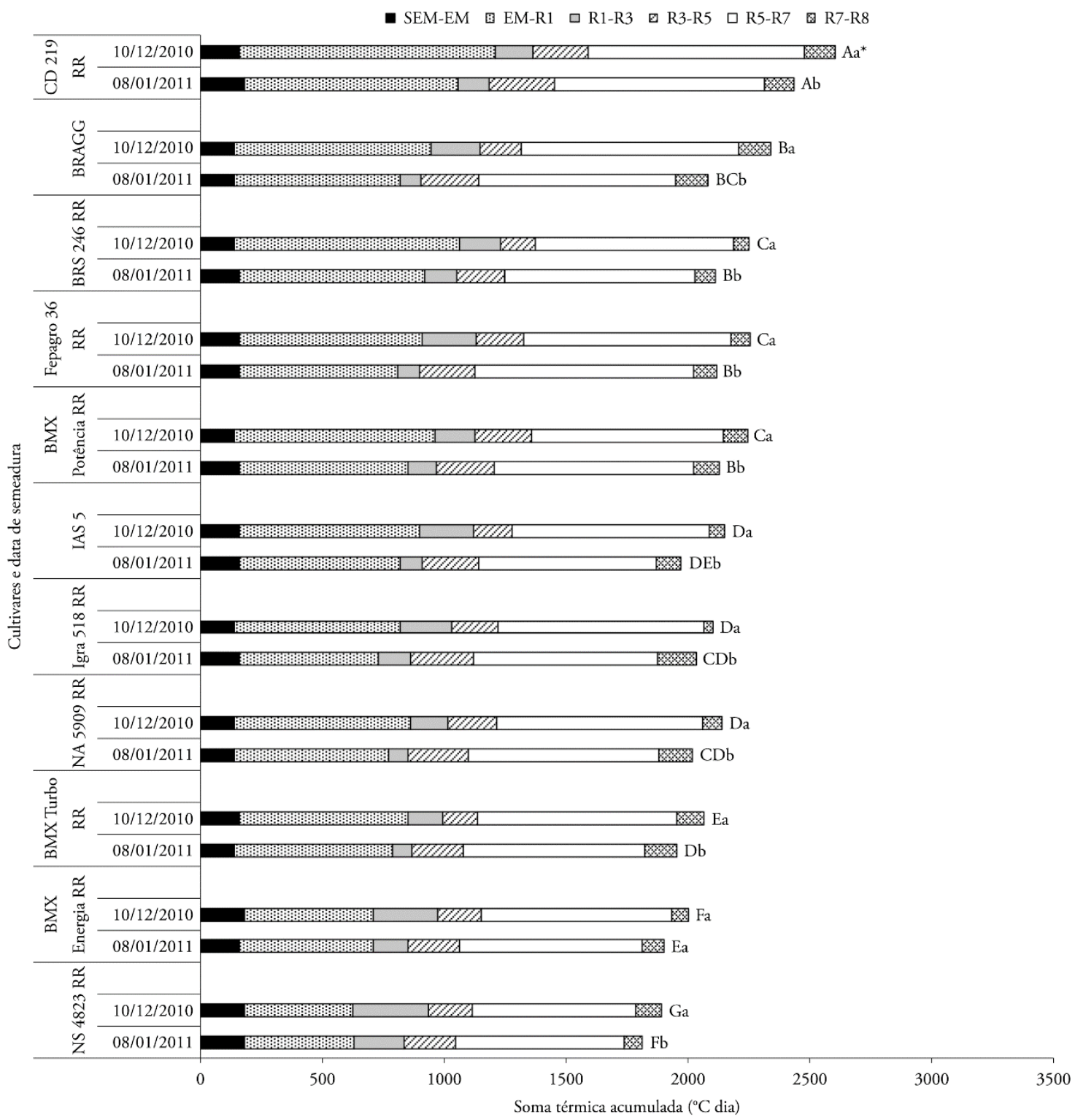

Figura 2. Duração, em ${ }^{\circ} \mathrm{C}$ dia, das fases semeadura-emergência (SEM-EM), emergência-R1 (EM-R1) e das subfases R1-R3, R3-R5, R5-R7 e R7-R8 de onze cultivares de soja, em duas datas de semeadura (10/12/2010 e 8/1/2011), no ano agrícola 2010-2011 em Santa Maria, RS. *Médias da duração do ciclo de desenvolvimento (EM-R8) seguidas pelas mesmas letras maiúsculas (comparação entre cultivares na mesma data de semeadura) e minúsculas (comparação de uma cultivar em diferentes datas de semeadura) não diferem entre si pelo Teste Duncan a $5 \%$ de probabilidade de erro.

da época preferencial, essas cultivares continuam crescendo em estatura até próximo ao início do enchimento de grãos (Bastidas et al., 2008), podendo, assim, serem utilizadas para viabilizar semeaduras antecipadas e tardias de soja no Rio Grande do Sul.

Em virtude da proximidade das datas de semeadura em Santa Maria (3/11/2012) e em Capão do Leão (9/11/2012), as onze cultivares apresentaram uma duração do ciclo de desenvolvimento similar (não diferiram significativamente) (Figura 5). Em Capão do Leão, a maioria das cultivares apresentaram uma menor duração da fase vegetativa e uma maior duração da fase reprodutiva, quando comparado às mesmas cultivares semeadas em Santa Maria. Uma das hipóteses para explicar esse resultado pode ser o número de dias que as cultivares semeadas em Capão do Leão (43 dias) ficaram expostas a fotoperíodo crescente na fase vegetativa, tempo esse menor do que as semeadas em Santa Maria (49 dias). Ou seja, as plantas em Capão do Leão foram induzidas mais rapidamente a transformar os meristemas vegetativos em reprodutivos, e consequentemente reduziram a duração da fase vegetativa e do ciclo total (Sinclair et al., 2005).

Nas cultivares com tipo de crescimento indeterminado, o período de sobreposiçáo entre a fase vegetativa e reprodutiva, foi maior do que nas cultivares com tipo de crescimento 


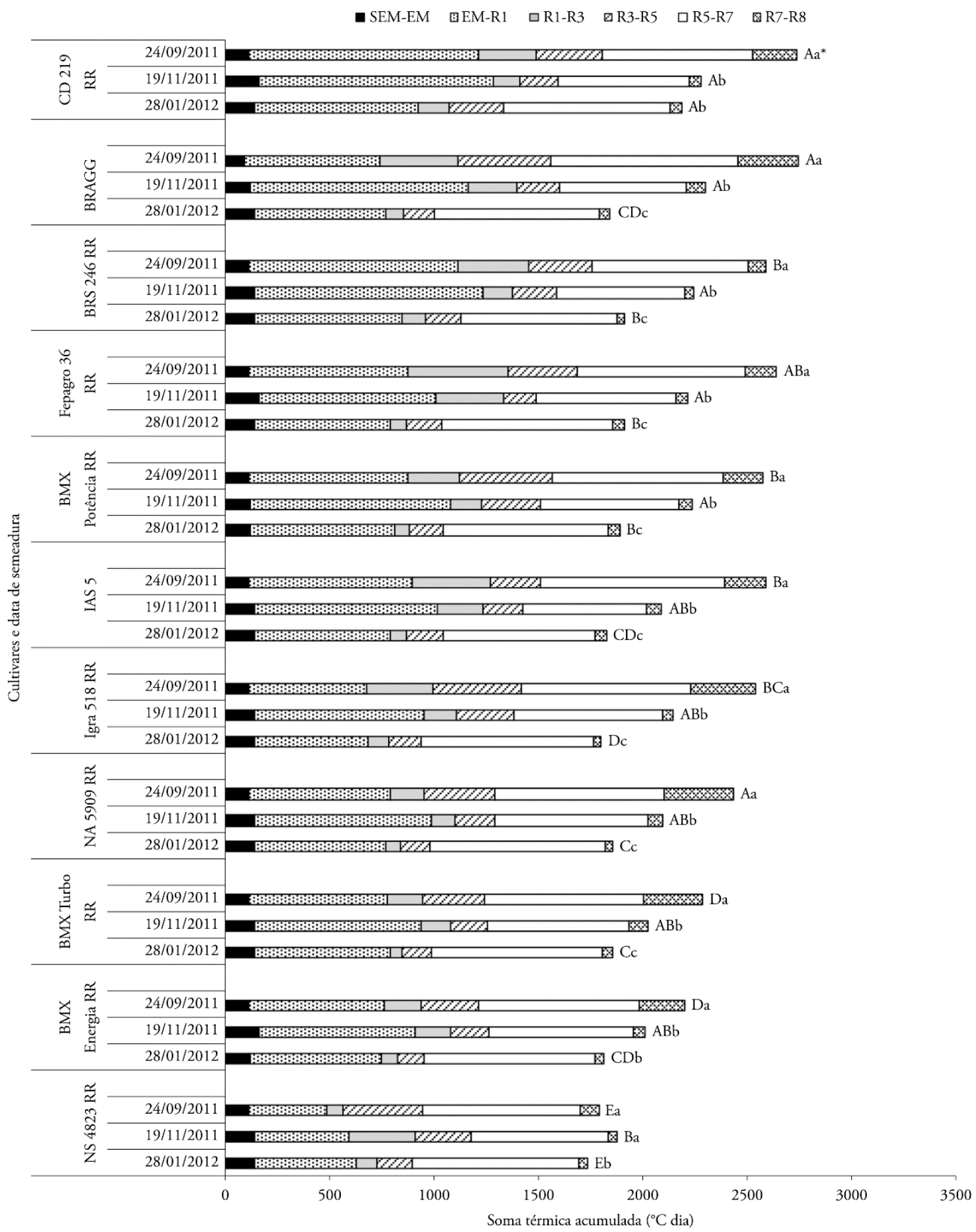

Figura 3. Duração, em ${ }^{\circ} \mathrm{C}$ dia, das fases semeadura-emergência (SEM-EM), emergência-R1 (EM-R1) e das subfases R1-R3, R3-R5, R5-R7 e R7-R8 de onze cultivares de soja, em três épocas de semeadura (24/9/2011, 19/11/2011 e 28/1/2012), no ano agrícola 2011-2012 em Santa Maria, RS. * Médias da duração do ciclo de desenvolvimento (EM-R8) seguidas pelas mesmas letras maiúsculas (comparação entre cultivares na mesma data de semeadura) e minúsculas (comparação de uma cultivar em diferentes datas de semeadura) não diferem entre si pelo Teste Duncan a 5\% de probabilidade de erro.

determinado, tanto em Santa Maria como em Capão do Leão (Figuras 6,7), concordando com os resultados encontrados por Bastidas et al. (2008), Setiyono et al. (2007) e Sinclair et al. (2005). A data de semeadura influenciou na duração do período de sobreposição, principalmente nas cultivares indeterminadas, havendo uma tendência de diminuição do período de sobreposição com o atraso da época de semeadura (Figuras 6b,c). O maior e o menor valor de sobreposição nas cultivares de tipo indeterminado foram na Igra 518 RR $\left(928,9^{\circ} \mathrm{C}\right.$ dia), semeada em 24/9/2011, e 


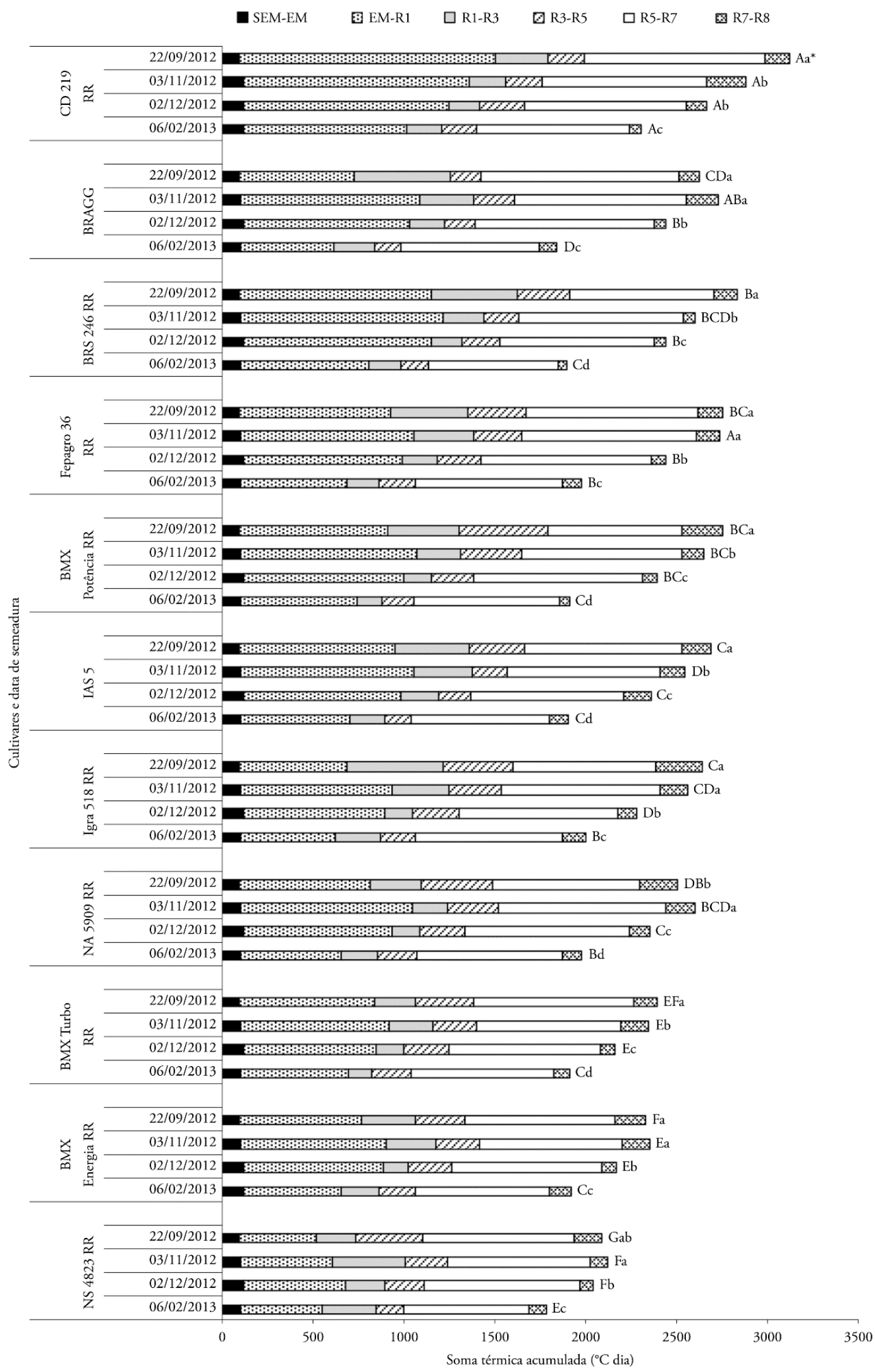

Figura 4. Duração, em ${ }^{\circ} \mathrm{C}$ dia, das fases semeadura-emergência (SEM-EM), emergência-R1 (EM-R1) e das subfases R1-R3, R3-R5, R5-R7 e R7-R8 de onze cultivares de soja, em quatro épocas de semeadura (22/9/2012, 3/11/2012, 2/12/2012 e 6/2/2013), no ano agrícola 2012-2013 em Santa Maria, RS. *Médias da duração do ciclo de desenvolvimento (EM-R8) seguidas pelas mesmas letras maiúsculas (comparação entre cultivares na mesma data de semeadura) e minúsculas (comparação de uma cultivar em diferentes datas de semeadura) não diferem entre si pelo Teste Duncan a 5\% de probabilidade de erro. 


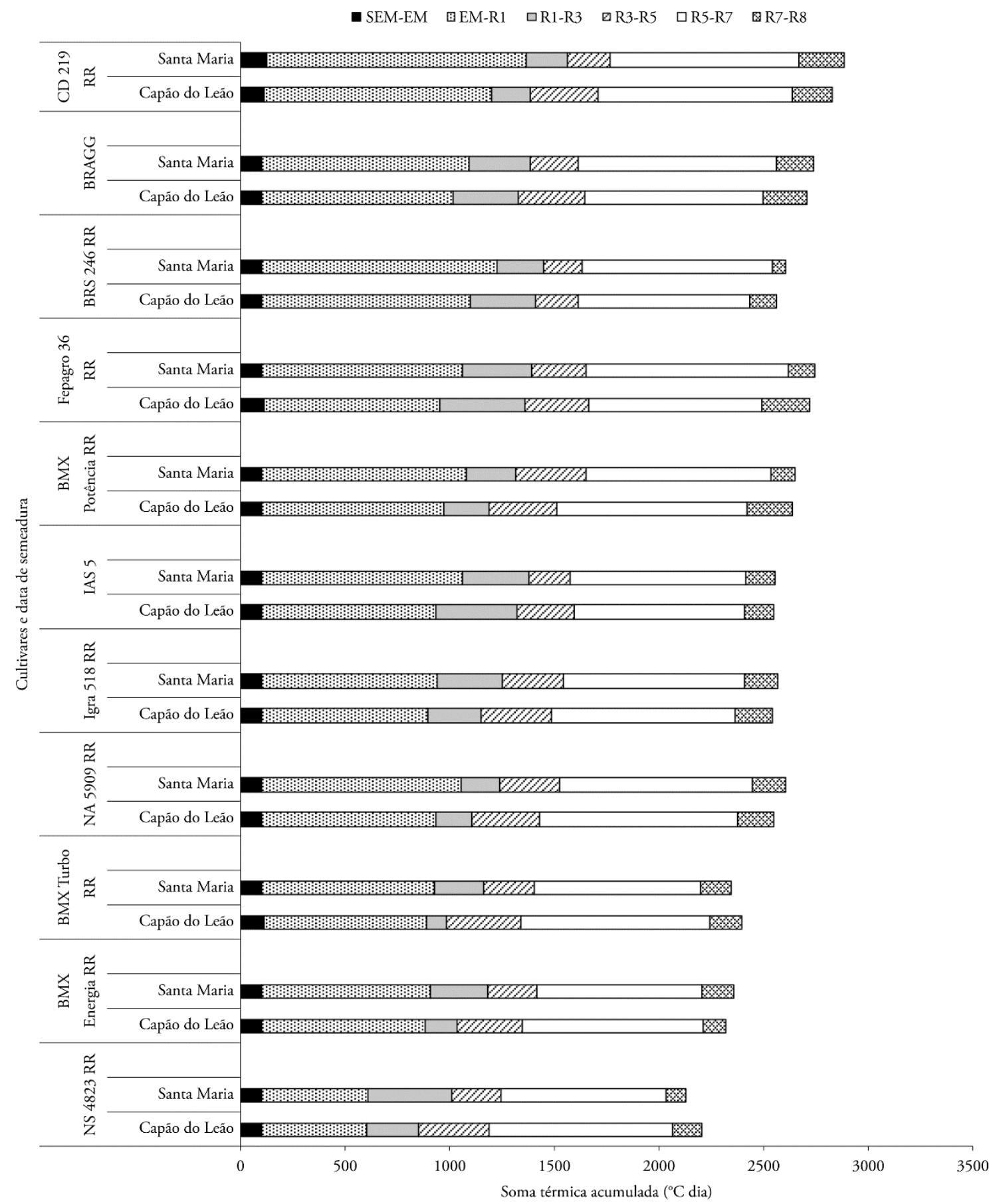

Figura 5. Duração, em ${ }^{\circ} \mathrm{C}$ dia, das fases semeadura-emergência (SEM-EM), emergência-R1 (EM-R1) e das subfases R1-R3, R3-R5, R5-R7 e R7-R8 de onze cultivares de soja, semeadas em Santa Maria (3/11/2012) e em Capáo do Leấo (9/11/2012), no ano agrícola 2012-2013 (RS).

na BMX Potência $\left(290,5^{\circ} \mathrm{C}\right.$ dia), semeada em 6/2/2013, respectivamente. Já nas cultivares de tipo determinado, o maior valor foi de $315,9^{\circ} \mathrm{C}$ dia na IAS 5 , semeada em 19/11/2011, e o menor, na CD 219RR ( $0^{\circ} \mathrm{C}$ dia), semeada em $22 / 9 / 2012$. A partir desses resultados verifica-se que as cultivares com tipo de crescimento determinado apresentaram algum período de sobreposição em todas as épocas e locais de cultivo, exceto a cultivar CD 219 RR, semeada em 22/9/2012 em Santa Maria.
O maior período de sobreposição entre a fase vegetativa e reprodutiva nas cultivares de tipo indeterminado pode conferir a elas maior capacidade de se adaptarem a diferentes épocas de semeadura. Apresentando maior capacidade de se recuperar de períodos curtos de estresse, como a ausência de chuvas, excesso hídrico no solo ou temperaturas elevadas. Esta é uma das possíveis explicações para os produtores de soja no RS atualmente semearem, principalmente, cultivares de soja com tipo de crescimento indeterminado, 


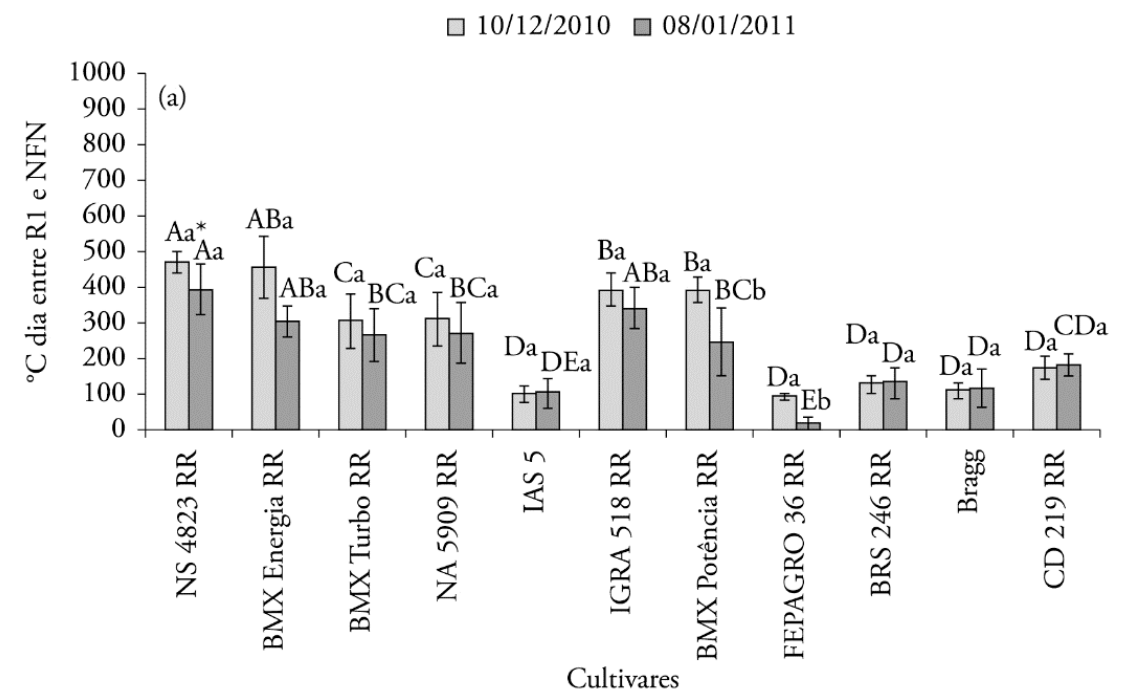

$\square 24 / 09 / 2011 \square 19 / 11 / 2011 \quad \square 29 / 01 / 2012$

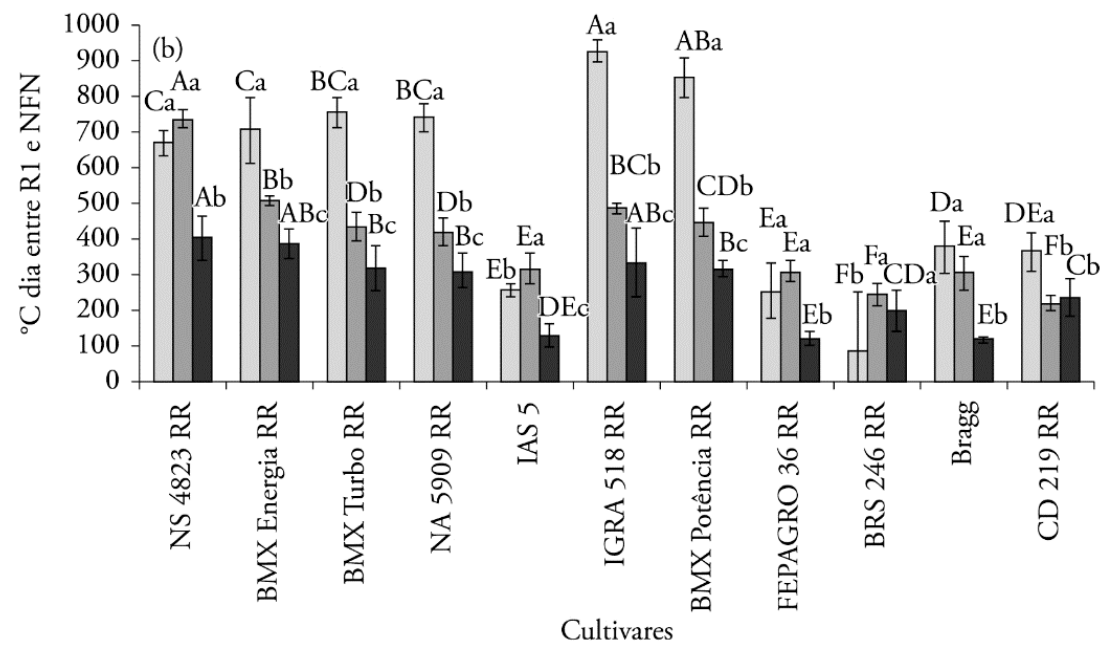

■ 22/09/2012 $\square 03 / 11 / 2012 \square 02 / 12 / 2012 \square 06 / 02 / 2013$

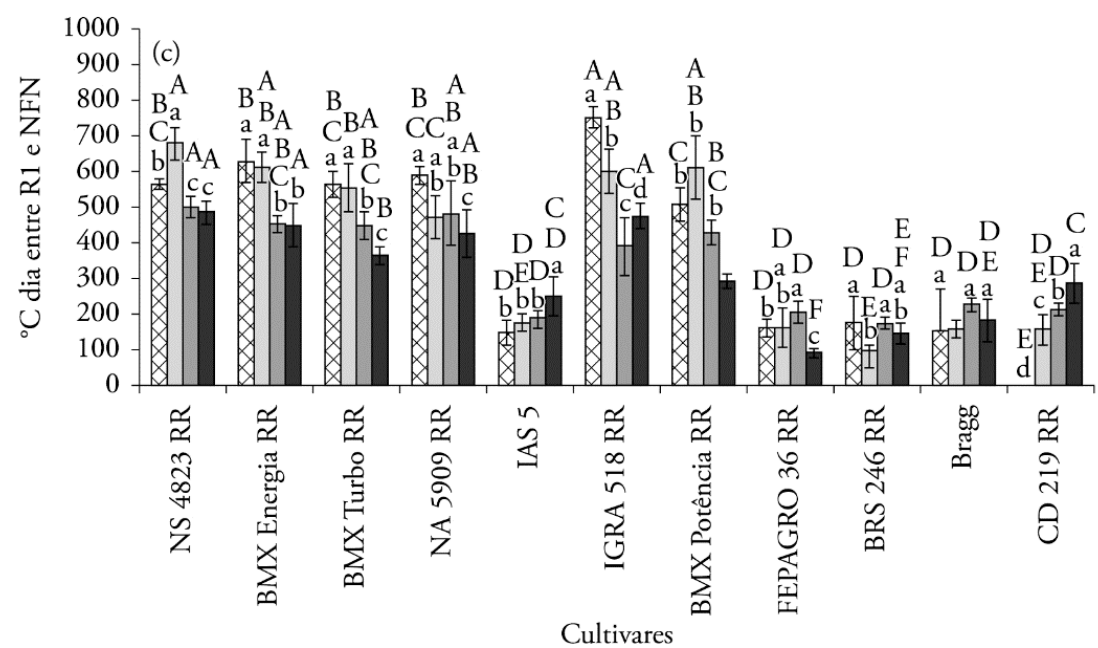

Figura 6. Sobreposição, em ${ }^{\circ} \mathrm{C}$ dia, entre o início do florescimento (R1) e o número final de nós (NFN) de onze cultivares de soja com tipo de crescimento determinado e indeterminado, em duas datas de semeadura (10/12/2010 e 8/01/2011) no ano agrícola 2010-2011 (a), três datas de semeadura $(24 / 9 / 2011,19 / 11 / 2011$ e 28/1/2012) no ano agrícola 2011-2012 (b), e quatro datas de semeadura (22/9/2012, 3/11/2012, 2/12/2012 e 6/2/2013) no ano agrícola 2012-2013 (c) nos experimentos em Santa Maria, RS. *Médias da sobreposiçáo entre o início do florescimento e o número final de nós seguida pelas mesmas letras maiúsculas (comparação entre cultivares na mesma data de semeadura) e minúsculas (comparação de uma cultivar em diferentes datas de semeadura) não diferem entre si pelo Teste Duncan a 5\% de probabilidade de erro. 


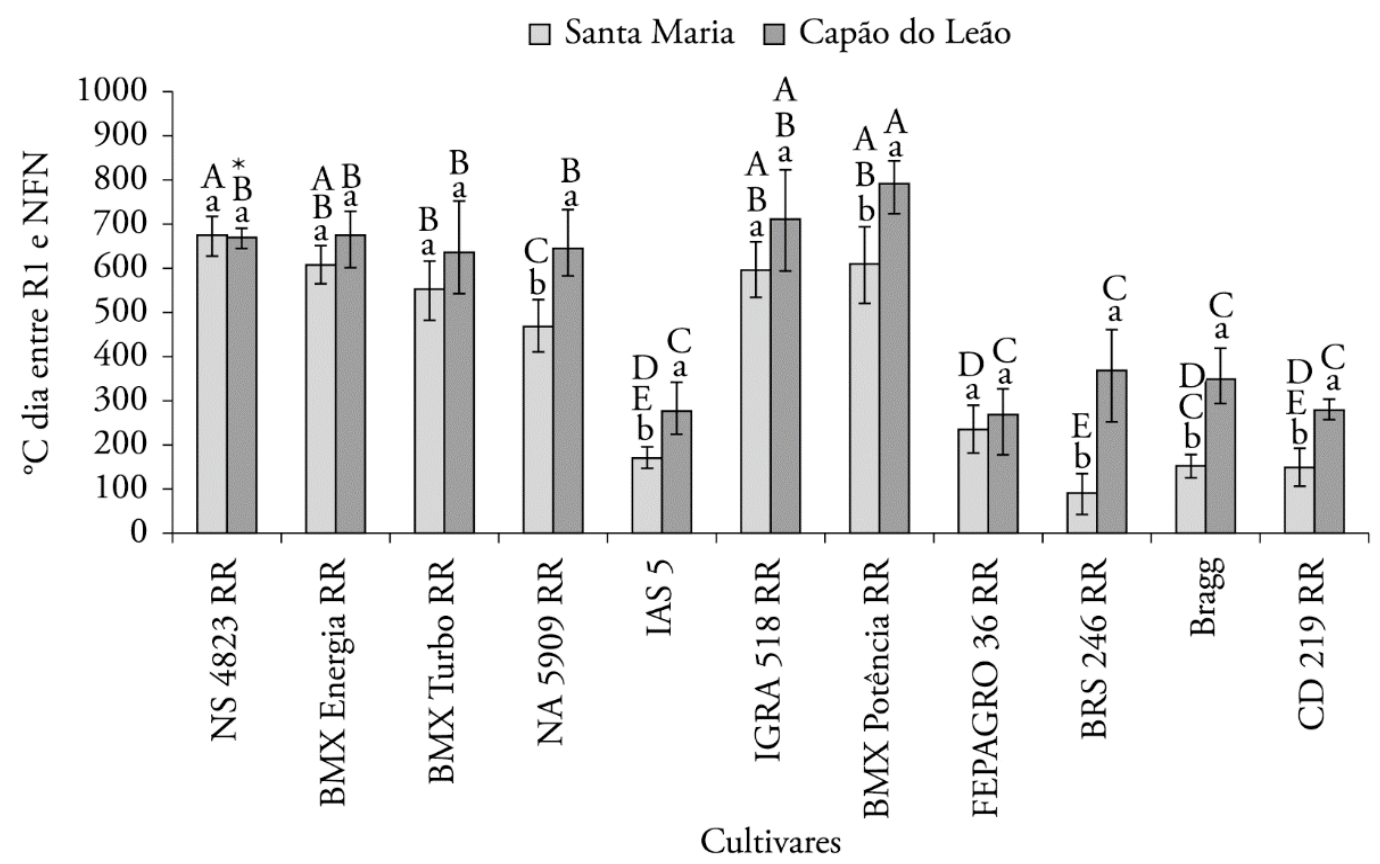

Figura 7. Sobreposição, em ${ }^{\circ} \mathrm{C}$ dia, entre o início do florescimento (R1) e o número final de nós (NFN) de onze cultivares de soja com tipo de crescimento determinado e indeterminado, semeadas em Santa Maria (3/11/2012) e em Capão do Leão (9/11/2012), no ano agrícola 2012-2013 (RS). *Médias da sobreposição entre o início do florescimento e o número final de nós seguida pelas mesmas letras maiúsculas (comparação entre cultivares no mesmo local de semeadura) e minúsculas (comparação de uma cultivar em diferentes locais de semeadura) não diferem entre si pelo Teste Duncan a $5 \%$ de probabilidade de erro.

diferentemente do que aconteceu desde a introdução da cultura da soja nesse Estado (1914) até o ano 2000, quando eram cultivadas, quase em sua totalidade, cultivares de tipo determinado (Barni \& Matznauer, 2000).

A similaridade na duração do ciclo de desenvolvimento das cultivares de soja, em Santa Maria (terras altas) e em Capão do Leão (terras baixas) (Figura 5), indica que o ambiente edáfico de cultivo não afeta o padrão de desenvolvimento em soja. Esta é uma importante informação para o Rio Grande do Sul, onde a área de cultivo de soja em terras baixas aumentou de 64 mil ha no ano agrícola 2010/2011 para 302 mil ha no ano agrícola 2013/2014 (IRGA, 2014), e pode continuar aumentando nos próximos anos em rotação com $\mathrm{o}$ arroz irrigado. Esses resultados indicam aos produtores $\mathrm{e}$ à assistência técnica que as práticas de manejo associadas ao desenvolvimento da soja em terras altas podem ser realizadas de forma muito similar em terras baixas, em virtude de não haver diferença na duraçáo das fases e do ciclo total de desenvolvimento da soja.

\section{CONCLUSÃO}

Há redução da duraçáo da fase reprodutiva, do ciclo total de desenvolvimento (exceto algumas cultivares semeadas em setembro), com o atraso da data de semeadura independentemente do grupo de maturação e tipo de crescimento. As semeaduras de setembro, janeiro e fevereiro promovem uma redução da fase vegetativa na maioria das cultivares quando comparadas com a época recomendada (novembro e dezembro).

Cultivares indeterminadas apresentam um maior período de sobreposição das fases vegetativa e reprodutiva do que as cultivares determinadas, em todas as épocas e locais de cultivo.

O desenvolvimento da soja é similar quando cultivada em terras altas e em terras baixas.

\section{REFERÊNCIAS}

Arnold, C. Y. (1960). Maximum-minimum temperature as a basis for computing heat units. Proceedings of the American Society for Horticultural Science, 76, 682-692.

Barni, N. A., \& Matznauer, R. (2000). Ampliação do calendário de semeadura da soja no Rio Grande do Sul pelo uso de cultivares adaptados aos distintos ambientes. Pesquisa Agropecuária Gaúcha, 6, 189-203.

Bastidas, A. M., Setiyono, T. D., Dorbemann, A., Cassman, K. G., Elmore, R. W., Graef, G. L., \& Specht, J. E. (2008). Soybean sowing date: the vegetative, reproductive, and agronomic impacts. Crop Science, 48, 727-740. http://dx.doi.org/10.2135/cropsci2006.05.0292.

Bonato, E. R., Bertagnolli, P. F., Ignaczak, J. C., Tragnago, J. L., \& Rubin, S. A. L. (1998). Desempenho de cultivares de soja em três 
épocas de semeadura, no Rio Grande do Sul. Pesquisa Agropecuaria Brasileira, 33, 879-884.

Companhia Nacional de Abastecimento - CONAB. (2014). Acompanhamento de safra brasileira: grãos (Quinto levantamento, p. 1-7). Brasília, DF: CONAB. Recuperado em 22 de abril de 2014, de www.conab.gov.br

Fehr, W. R., \& Caviness, C. E. (1977). Stages of soybean development (Special Report, 80). Ames: Iowa State University of Science and Technology. $15 \mathrm{p}$.

Gomes, F. P. (1990). Curso de estatística experimental (13 ed.). Piracicaba: Nobel. 468 p.

Grimm, S. S., Jones, J. W., Boote, K. J., \& Herzog, D. C. (1994). Modeling the occurrence of reproductive stages after flowering for four soybean cultivars. Agronomy Journal, 86, 31-38. http://dx.doi. org/10.2134/agronj1994.00021962008600010007x.

Instituto Rio Grandense do Arroz - IRGA. (2014). Levantamento de área semeada com soja em terras baixas no Rio Grande do Sul, 2014. Porto Alegre: IRGA. Recuperado em 20 de junho de 2014, de http://www.irga.rs.gov.br

Kantolic, A. G. (2008). Control ambiental y genético de la fenologia del cultivo de soja: impactos sobre elrendimiento y laadaptación de genótipos. Revista da Facultad de Agronomía UBA, 28, 63-88.

Kantolic, A. G., \& Slafer, G. A. (2005). Reproductive development and yield components in indeterminate soybean as affected by postflowering photoperiod. Field Crops Research, 93, 212-222. http:// dx.doi.org/10.1016/j.fcr.2004.10.001.

Kantolic, A. G., Mercau, J. L., Slafer, G. A., \& Sadras, V. O. (2007). Simulated yield advantages of extending post-flowering development at the expense of a shorter pre-flowering development in soybean. Field Crops Research, 101, 321-330. http://dx.doi.org/10.1016/j. fcr.2006.12.008.

Kuinchtner, A., \& Buriol, G. A. (2001). Clima do estado do Rio Grande do Sul segundo a classificação climática de Köppen e Thornthwaite. Disciplinarum Scientia., 2, 171-182.
Meotti, G. V., Benin, G., Silva, R. R., Beche, E., \& Munaro, L. B. (2012). Épocas de semeadura e desempenho agronômico de cultivares de soja. Pesquisa Agropecuaria Brasileira, 47, 14-21. http://dx.doi. org/10.1590/S0100-204X2012000100003.

Mercau, J. L., Dardanelli, J. L., Collino, D. J., Andriani, J. M., Irigoyen, A., \& Satorre, E. H. (2007). Predicting onfarm soybean yields in the pampas using CROPGROsoybean. Field Crops Research, 100, 200209. http://dx.doi.org/10.1016/j.fcr.2006.07.006.

Setiyono, T. D., Cassman, K. G., Specht, J. E., Dobermann, A., Weiss, A., Yang, H., Conley, S. P., Robinson, A. P., Pedersen, P., \& De Bruin, J. L. (2010). Simulation of soybean growth and yield in near-optimal growth conditions. Field Crops Research, 119, 161-174. http://dx.doi.org/10.1016/j.fcr.2010.07.007.

Setiyono, T. D., Weiss, A., Specht, J. E., Bastidas, A. M., Cassman, K. G., \& Dobermann, A. (2007). Understanding and modeling the effect of temperature and daylenght on soybean phenology under high-yield conditions. Field Crops Research, 100, 257-271. http:// dx.doi.org/10.1016/j.fcr.2006.07.011.

Sinclair, T. R., Neumaier, N., Farias, J. R. B., \& Nepomuceno, A. L. (2005). Comparison of vegetative development in soybean cultivars for low latitude environments. Field Crops Research, 92, 53-59. http://dx.doi.org/10.1016/j.fcr.2004.08.008.

Streck, E. V., Kampf, N., Dalmolin, R. S. D., Klamt, E., Nascimento, P. C., Schneider, P., Giasson, E., \& Pinto, L. F. S. (2008). Solos do Rio Grande do Sul. Porto Alegre: EMATER. 126 p.

Stülp, M., Branccini, A. L., Albrecht, L. P., Ávila, M. R., Scapim, C. A., \& Schuster, I. (2009). Desempenho agronômico de três cultivares de soja em diferentes épocas de semeadura em duas safras. Ciência e Agrotecnologia, 33, 1240-1248. http://dx.doi.org/10.1590/S141370542009000500006 .

Trentin, R., Heldwein, A. B., Streck, N. A., Trentin, G., \& Silva, J. C. (2013). Subperíodos fenológicos e ciclo da soja conforme grupos de maturidade e datas de semeadura. Pesquisa Agropecuaria Brasileira, 48, 703-713. http://dx.doi.org/10.1590/S0100-204X2013000700002. 